\title{
Diffusion tensor imaging of brain white matter in Huntington gene mutation individuals
} Imagem por tensor de difusão em indivíduos com mutação do gene da doença de Huntington Roberta Arb Saba ${ }^{1}$, James H. Yared ${ }^{1}$, Thomas M. Doring, Med Phys ${ }^{1}$, Vanderci Borges ${ }^{1}$, Henrique Ballalai Ferraz¹

\begin{abstract}
Objective: To evaluate the role of the involvement of white matter tracts in huntingtin gene mutation patients as a potential biomarker of the progression of the disease. Methods: We evaluated 34 participants (11 symptomatic huntingtin gene mutation, 12 presymptomatic huntingtin gene mutation, and 11 controls). We performed brain magnetic resonance imaging to assess white matter integrity using diffusion tensor imaging, with measurement of fractional anisotropy. Results: We observed a significant decrease of fractional anisotropy in the cortical spinal tracts, corona radiate, corpus callosum, external capsule, thalamic radiations, superior and inferior longitudinal fasciculus, and inferior frontal-occipital fasciculus in the Huntington disease group compared to the control and presymptomatic groups. Reduction of fractional anisotropy is indicative of a degenerative process and axonal loss. There was no statistically significant difference between the presymptomatic and control groups. Conclusion: White matter integrity is affected in huntingtin gene mutation symptomatic individuals, but other studies with larger samples are required to assess its usefulness in the progression of the neurodegenerative process.
\end{abstract}

Keywords: Huntington disease; biomarkers; neuroimaging.

\section{RESUMO}

Objetivo: Avaliar o envolvimento da substância branca (SB) cerebral em indivíduos com mutação do gene da huntingtina. Métodos: Foram avaliados 34 indivíduos: 11 com mutação do gene da huntingtina sintomática, 12 assintomáticos com mutação do gene da huntingtina e 11 indivíduos controles. Realizamos ressonância magnética cerebral para avaliar a integridade da SB usando o tensor de difusão (DTI), com medição da anisotrofia fracionada (FA). Resultados: Observamos uma diminuição da FA no trato corticoespinhal, coroa radiada, corpo caloso (joelho, corpo e esplênio), cápsula externa, radiações talâmicas, fascículo longitudinal superior e inferior, e fascículo frontal-occipital inferior no grupo dos indivíduos com mutação sintomática. A redução da FAé indicativa de processo degenerativo e perda axonal. Não houve diferença estatística entre os grupos controle e pré-sintomático. Conclusão: Houve comprometimento da integridade da SB em indivíduos com mutação no gene da Huntingtina sintomática, mas outros estudos são necessários para avaliar a sua utilidade na progressão do processo neurodegenerativo.

Palavras-chave: doença de Huntington; biomarcadores; neuroimagem

Huntington's disease (HD) is a genetic disorder characterized by motor, psychiatric, and cognitive impairments. Understanding the pathophysiology of $\mathrm{HD}$, the role of the structures and pathways involved in its pathogenesis, as well as identification of relevant biomarkers, may pave the way for better disease management and control. Neuroimaging techniques for HD evaluate structural, functional, and metabolic changes ${ }^{1}$.

Initially, structural imaging studies assessed the degree of striatum (caudate nucleus and putamen) atrophy in patients with HD, and it has been shown that atrophy of this area occurs up to 15 to 20 years before the HD onset ${ }^{2,3}$, presenting a pattern of rapid and almost linear impairment over time. However, the degeneration of the brain in HD extends far beyond the striatum, involving both cortical and subcortical regions. The involvement of the cerebral cortex has been of particular interest because mutant huntingtin protein aggregates concentrate beyond the striatum ${ }^{4}$. Neuroimaging techniques have been used to evaluate structural, functional and metabolic changes in $\mathrm{HD}^{5,6}$.

Diffusion tensor imaging (DTI) is a method that uses magnetic resonance imaging (MRI) to measure changes in tissue composition. Quantitative measures of DTI, such as fractional anisotropy (FA) and axial diffusivity (AD), provide

1 Universidade Federal de São Paulo, Escola Paulista de Medicina, Disciplina de Neurologia, São Paulo SP, Brasil.

Correspondence: Henrique Ballalai Ferraz; Rua Pedro de Toledo, 650 / 10 andar; 04039-002 São Paulo SP, Brasil; E-mail: henrique_ferraz@uol.com.br Conflict of interest: There is no conflict of interest to declare.

Support: We thank Diagnósticos da América (DASA) for performing the magnetic resonance imaging in all participants and Dr. Nelson Fortes for allowing us to use the DASA equipment to evaluate the imaging.

Received 09 November 2016; Received in final form 10 March 2017; Accepted 15 April 2017. 
information about white matter integrity and can evaluate the architecture of gray matter. More specifically, FA measures the degree to which fibers in a given voxel are oriented in the same direction. Thus, a high FA indicates greater fiber organization. On the other hand, a reduced FA, such as that described in patients with $\mathrm{HD}^{6}$, suggests white matter degeneration. Specifically, a reduction in white matter volume may suggest a decrease in the number of axons within an affected region, a decrease in the amount of myelin surrounding axons, or both ${ }^{5}$. Moreover, damage of oligodendrocytes and axonal membranes, along with interrupted axonal transport due to the presence of mutant huntingtin and increased microglia reactivity, have been described in the pathophysiological context of HD and may be the cause of FA abnormalities $^{6}$. Finally, previous studies have shown that FA and AD are effective in analyzing cortex, striatum, and white matter microstructures in individuals with $\mathrm{HD}^{7,8}$.

Kloppel et al. performed a study on FA maps to determine which voxels could correctly identify individuals as presymptomatic mutation carriers or controls 9 . They found a reduction in connectivity between the caudate body and the frontal cortex in presymptomatic patients. This study was the first to use DTI to identify possible biomarkers of HD, as well as to explore the structure-function relationship of brain regions in presymptomatic individuals with $\mathrm{HD}^{9}$.

The observation that the loss of white matter and atrophy of the striatum correlate with motor and neuropsychological performance suggests that combined structural imaging measures may be effective biomarkers of $\mathrm{HD}^{10}$. Moreover, a recent analysis (subgroup of TRACK-HD) showed that changes in white matter connections of the sensorimotor cortex are correlated with the phenotypic deterioration associated with $\mathrm{HD}$, and that these changes could be used to estimate the imminent onset of symptoms in asymptomatic individuals with mutant huntingtin ${ }^{11}$.

Although the diagnosis of $\mathrm{HD}$ is performed through a molecular test, there is no marker for the progression of symptoms, which would allow for the objective evaluation of drug efficacy and action in presymptomatic patients.

We aimed to evaluate the use of DTI in the analysis of white matter tracts as a potential biomarker of the progression of the degenerative process in individuals with mutations of the Huntington gene.

\section{METHODS}

The 40 participants selected for this study either had a family history of HD or exhibited symptoms that were strongly indicative of the disease. These individuals were submitted to imaging studies and clinical evaluations, which included the Unified Huntington's Disease Rating Scale -motor part, validated to the Portuguese language ${ }^{12,13}$; the Mini Mental State Examination ${ }^{14}$; Montreal Cognitive Assessment; and the Beck Depression Scale ${ }^{15,16}$. Mean scores of the scales employed are shown in the Table.

Of the 40 participants, four were excluded due to issues with imaging acquisition and two due to a further diagnosis of HD-like 2.

The remaining 34 participants underwent molecular testing for HD.

These 34 participants were divided into three groups: 11 patients with symptomatic huntingtin gene mutation (Huntington's disease); 12 individuals with presymptomatic huntingtin gene mutation (without behavioral symptoms, cognitive impairment, or abnormal involuntary movements, but with a positive test result) with a maximum score of 5 on the Unified Huntington's Disease Rating Scale - motor part ${ }^{17}$; and 11 control individuals. The average duration of the disease in the HD group was 5.6 years (2-16 years).

\section{Ethics, consent and permissions}

All patients were informed about the objective of the study and freely signed an informed consent form. This study was submitted to and approved by the Ethics Committee in Research of UNIFESP (CEP \#1614/11) and all national specific laws on ethics in medical research have been observed. All subjects included in the research consented and allowed us to publish, in scientific meetings and journals, the results of this study.

\section{Image acquisition and processing}

Participants underwent a non-contrasted MRI scan of the brain for up to nine minutes to measure white matter parameters. Examinations were performed in a Siemens MAGNETOM ESPREE 1.5T scanner with SyngoDTI tractography. This technique uses diffusion tensor data, and allows for the three-dimensional viewing of specific white matter tracts. A gradient echo with an echo planar imaging readout

Table. Clinical and demographic characteristics of the study participants.

\begin{tabular}{|c|c|c|c|c|c|c|c|}
\hline Variable & $\mathrm{n} / \mathrm{Sex}$ & $\begin{array}{c}\text { Age } \\
\text { (in years) }\end{array}$ & $\begin{array}{l}\text { Number of } \\
\text { CAG repeats }\end{array}$ & $\begin{array}{l}\text { MoCA } \\
\text { score }\end{array}$ & $\begin{array}{l}\text { MMSE } \\
\text { score }\end{array}$ & $\begin{array}{l}\text { UHDRS } \\
\text { motor score }\end{array}$ & BDS \\
\hline Controls & $7 F / 4 M$ & 33.1 & 17.9 & 27.5 & 29.5 & 0.72 & 8.9 \\
\hline HD & $6 \mathrm{~F} / 5 \mathrm{M}$ & 45.7 & 44.2 & 15.2 & 21.2 & 39 & 19.2 \\
\hline Pre-symptomatic & $6 \mathrm{~F} / 6 \mathrm{M}$ & 34.7 & 41.7 & 25.3 & 28.6 & 1.3 & 4.5 \\
\hline
\end{tabular}

Note: All subjects were heterozygous for Huntington's disease (HD). F: Female; M: Male; MoCA: Montreal Cognitive Assessment; MMSE: mini-mental state examination; UHDRS: Unified Huntington's Disease Rating Scale; BDS: Beck Depression Scale. 
sequence was applied in 30 directions, one $b=0.2-\mathrm{mm}$ slices, and $30 \times \mathrm{b}=900 \mathrm{~s}^{2} / \mathrm{mm}$. The software used was Syngo DTI Evaluation for the quantitative evaluation of the frequency and direction of water movement inside a voxel (2.3 $\mathrm{mm})$, calculation of different diffusion parameters based on specific regions of interest, and construction of colored diffusion maps (e.g. FA maps). The DTI images were analyzed using the diffusion toolbox that accompanies the FSL 4.1 software (http:// www.fmrib.ox.ac.uk/fsl) ${ }^{18}$. Images were evaluated for Eddy current correction distortion and brain extraction, and FA images were created for all subjects via diffusion tensor calculation. Individual FA maps were registered using a non-linear algorithm, which uses a b-spline representation of the registration warp field ${ }^{19}$. The FMRIB58 standard-space was used as reference (target) for the registration (http://www.fmrib.ox.ac. uk/fsl/data/FMRIB58_FA.html). Next, an average FA image of all individuals was created and from this, an average FA skeleton, representing the center of all tracts that a group had in common, was constructed. Individual FA images were then aligned and projected onto this skeleton to obtain a resulting image that was used to perform voxel-wise statistics between individuals; FA > 0.3 was used to exclude peripheral tracts due to significant variability among individuals.

\section{Statistical method}

Voxel-wise statistical analysis of FA images was performed using tract-based spatial statistics (TBSS ${ }^{20}$, which is part of the FSL 4.1 software. To produce significance maps, a voxel-wise analysis was performed using inference based on permutations (5,000 permutations) and threshold-free-cluster-enhancement. The significance level was set at $\mathrm{p}<0.05$ and corrected by multiple comparisons ( family-wise error). Maps of significance "p" were generated to identify differences in areas of FA between patients with HD, presymptomatic individuals, and controls.

Green outlines showed the areas used for statistical analysis. After obtaining white matter integrity data, we compared FA values across the three groups.

\section{RESULTS}

We found a statistically significant reduction in FA values of the symptomatic HD group when compared with presymptomatic and control individuals. Tracts affected were the genu, truncus, and splenium of the corpus callosum, fornix, corticospinal tract, anterior and posterior corona radiate, anterior and posterior thalamic radiations, external capsule, inferior longitudinal fasciculus, and inferior fronto-occipital fasciculus. The superior longitudinal and uncinate fasciculus presented a reduction of FA in the HD group, but only when these values were compared to controls and not presymptomatic participants. Figures 1 and 2 show the tracts that displayed a reduction of FA, in yellow.
There was no statistically significant difference between the presymptomatic and the control group.

\section{DISCUSSION}

White matter degeneration is increasingly being postulated as an important feature in the progression of HD. The use of innovative imaging techniques, such as DTI with TBSS and tractography, allow for a more accurate and detailed analysis of the progression of white matter degeneration, and can provide valuable information, even before an established HD diagnosis. The HD mutation can affect neuronal development, leading to structural differences and diffusion abnormalities. However, previous studies have revealed that changes in diffusivity and FA are correlated with clinical severity and cognitive performance, and individuals with established HD exhibit more extensive alterations than those in presymptomatic stages of the disease ${ }^{6,21}$. Taken together, these studies indicate that HD pathology involves progressive structural degeneration.

Our data showed degeneration of many white matter tracts in patients with HD when compared to controls and presymptomatic individuals; however, we could not demonstrate differences between the presymptomatic and the control groups. Our results are different from what we expected and may have been biased because of the small sample size or because of the $1.5 \mathrm{~T}$ technique used; studies with a 3-T scanner are necessary to clarify this issue. Alternatively, this could indicate that degenerative processes start concomitant to the development of symptoms.

In the current study, we used the TBSS statistical test to overcome difficulties in aligning diffusion data across subjects. Using this approach allowed us to conduct an objective voxel-wise analysis of regional changes in brain-wide white matter. One disadvantage of this method is that smaller lesions may not have been captured due to alignment issues. However, this study was not the first to use diffusion imaging methods in presymptomatic patients with HD. For instance, increased diffusion has been observed in carriers of the mutant HD gene in periventricular and striatal white matter ${ }^{22}$. Another study that applied a voxel-based analysis on presymptomatic individuals showed a decrease in white matter FA in the superior frontal, medial frontal, postcentral, and precentral regions ${ }^{6}$. Rosas et al. $^{6}$, using a manually-adjusted region of interest, demonstrated a reduction of FA in the corticospinal tract and corpus callosum in presymptomatic individuals with HD. Moreover, Stoffers et al. ${ }^{23}$ used tractography to assess modifications in both gray matter and white matter in presymptomatic subjects, and showed a decrease in the volume of both. More specifically, they reported a change in gray matter specific to the basal ganglia-thalamocortical pathways, but a more widespread deterioration of white matter. In accordance with abnormalities found in the gray 


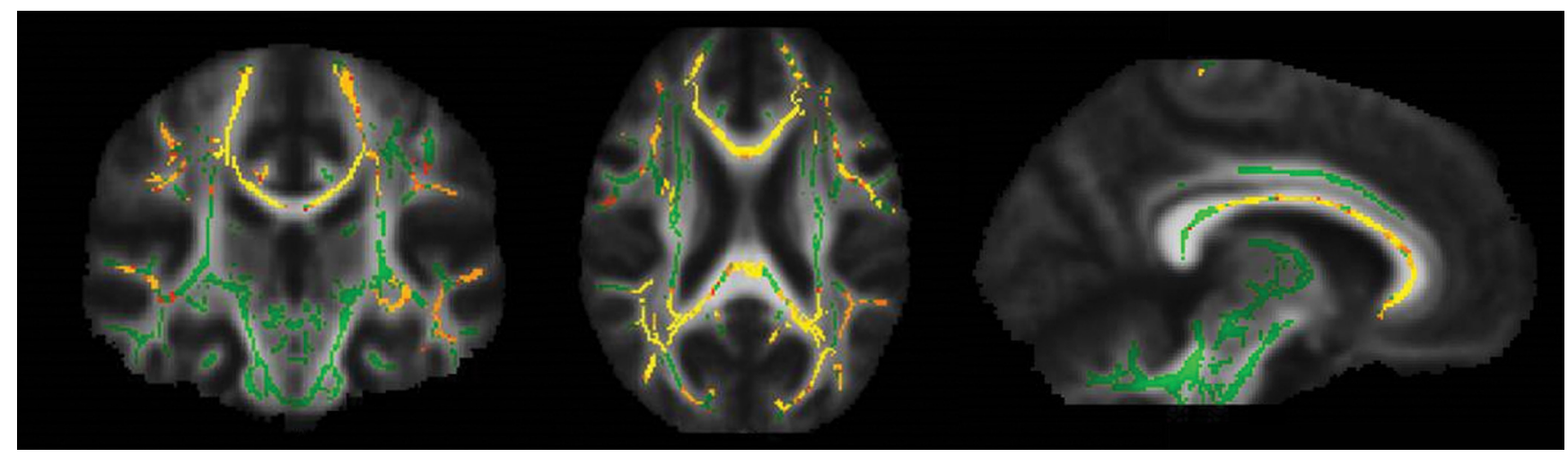

Figure 1. Huntington disease patients versus control individuals. Yellow areas show a significant reduction of fractional anisotropy in patients with Huntington disease compared to that in controls ( $p<0.05)$. Tracts with reduced fractional anisotropy: genu, truncus, and splenium of the corpus callosum; fornix; corticospinal tract; anterior and posterior corona radiate; anterior and posterior thalamic radiations; external capsule; uncinate fasciculus; inferior longitudinal fasciculus; and inferior fronto-occipital fasciculus.

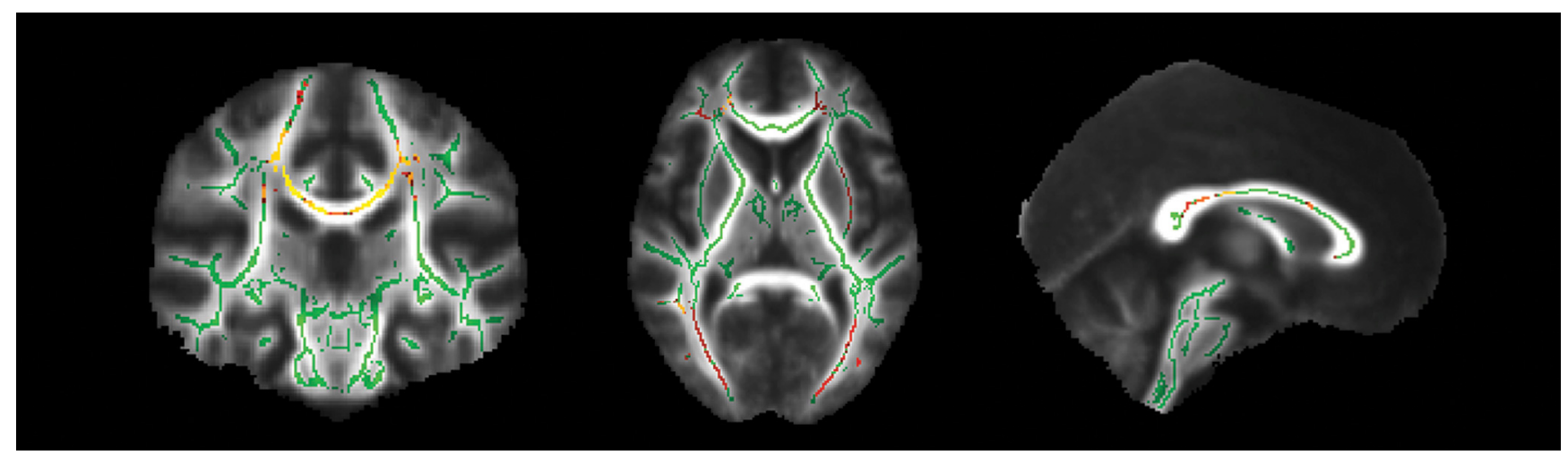

Figure 2. Huntington disease patients versus presymptomatic individuals. Yellow areas show a significant reduction of fractional anisotropy in patients with Huntington disease compared to that in presymptomatic partients $(p<0.05)$. Tracts with reduced fractional anisotropy: genu, truncus, and splenium of the corpus callosum; anterior and posterior corona radiate; and inferior fronto-occipital fasciculus.

matter (in areas such as the motor cortex), the TBSS analysis conducted by Stoffers et al. ${ }^{23}$ showed that presymptomatic individuals exhibited reduced anisotropy in the major output of the corticospinal tract. However, they reported extensive white matter changes, such as those involving the superior and inferior longitudinal fasciculus, and these regions do not relate to the loci of the gray matter change. This suggests that the loss of white matter tract integrity is not merely a consequence of gray matter atrophy. Finally, when a correlation analysis was performed on the FA and "estimated years to symptom onset”, Stoffers et al. ${ }^{23}$ reported a more reduced FA value in presymptomatic subjects closest to the "estimated onset". Although we used similar image acquisition techniques, we did not longitudinally examine the time of symptom onset in presymptomatic subjects, which might explain why we did not find statistically significant differences when comparing presymptomatic individuals with control subjects.

A study conducted by Novak et al. ${ }^{24}$ reported reduced white matter FA in presymptomatic and HD groups compared to controls. Their analysis revealed that the greatest
FA reductions occur in the bilateral corpus callosum, cingulum, superior and inferior longitudinal fasciculi, short perforating fibers, and internal and external capsules. The authors observed that there was an extensive area of compromised white matter in individuals with HD and that these altered diffusivity parameters could serve as markers of disease severity. Novak et al. also evaluated white matter $\mathrm{AD}$ and caudate nucleus volume and postulated that white matter microstructural alterations in individuals with HD are related to changes in caudate nucleus volume and in the white matter tracts directly related to this nucleus. Further, it is possible that white matter degeneration occurs as a direct result of caudate nucleus atrophy. Our current data support the hypothesis that the degeneration of white matter microstructures precedes macroscopic changes (volumetric) ${ }^{24}$.

Another study, using DTI, evaluated and compared FA, $\mathrm{AD}$, and diffusivity of perpendicular and parallel fibers and showed a significant reduction in FA and increase in $\mathrm{AD}$ in patients with HD compared to controls. These changes were specific to the corpus callosum, fornix, external and internal capsules, corona radiate, and sagittal stratum. In addition, the 
FA was significantly reduced in the left posterior thalamic radiation and left superior longitudinal fasciculus. Abnormalities in the corticospinal and interhemispheric tracts affect motor and cognitive functions in individuals with $\mathrm{HD}$.

The interhemispheric connection between the sensory and motor cortex through the corpus callosum is crucial for coordinated movement. Of equal importance are prefrontal regions that are interconnected with the corpus callosum, as their impairment could have negative consequences on cognitive function ${ }^{25}$. Rosas et al. $^{6}$ showed that presymptomatic patients can be differentiated from controls based on the FA value that corresponds to the genu of the corpus cal$\operatorname{losum}^{25}$. The microstructure of the corpus callosum has also been shown to be involved in the clinical symptoms of HD, as Rosas et al. ${ }^{6}$ demonstrated reduced FA values in the genu, truncus, and splenium of patients with $\mathrm{HD}$, while presymptomatic individuals only exhibited reduced FA in the truncus of the corpus callosum ${ }^{6}$. The corpus callosum has been thoroughly studied in HD, since it is the main area of information transfer between the brain hemispheres and is involved in executive function and non-spatial working memory, both of which are deficient in presymptomatic individuals. Moreover, diffusion abnormalities in the corpus callosum may represent pathological changes in the cerebral cortex ${ }^{8}$. Our current work showed involvement of the corpus callosum; thus, microstructural changes in the corpus callosum could prove a promising target to better understand how alterations in this tract correlate with HD-related cognitive and motor changes.

Longitudinal analyses using DTI with TBSS are promising to improve our understanding of the progression of HD. In fact, a study that employed the TBSS technique on a relatively small sample size was the first to suggest longitudinal white matter degeneration in individuals with $\mathrm{HD}^{26}$. A recent study on a larger sample aimed to quantify changes in white matter microstructures in presymptomatic patients and patients with HD before and after an 18-month period ${ }^{27}$. This study showed a reduction of FA in the corpus callosum and in the cingulum of presymptomatic individuals compared with individuals with HD. Moreover, the reduced FA of the genu, truncus, and splenium of the corpus callosum is significantly correlated with motor scores of the Unified Huntington's Disease Rating Scale in both HD groups. This measure is also the only independent predictor of a longitudinal decline in FA in all parts of the corpus callosum in both HD groups, suggesting that the loss of axonal integrity is an early indication of neurodegenerative changes. Although the abovementioned study revealed no longitudinal changes in presymptomatic individuals, the clinical symptoms and alterations in motor function predicted important microstructural white matter changes for all individuals genetically positive for HD. Thus, use of the TBSS to measure FA in the current study enabled us to analyze specific pathways of interest with more accuracy, providing greater credibility to our results, and allowing us to suitably observe white matter microstructure and connection changes.

In conclusion, by using the DTI technique, HD patients exhibited extensively impaired white matter tracts, leading us to propose that changes in the diffusion parameters were associated with markers of the severity of the disease. On the other hand, we could not identify abnormalities in the presymptomatic phase of HD and further studies are necessary to identify whether DTI is a useful tool for the follow-up of the degenerative process of HD.

\section{References}

1. Weir DW, Sturrock A, Leavitt BR. Development of biomarkers for Huntington's disease. Lancet Neurol 2011;10(6):573-90. https://doi.org/10.1016/S1474-4422(11)70070-9

2. Paulsen JS, Langbehn DR, Stout JC, Aylward E, Ross CA, Nance M et al. Detection of Huntington's disease decades before diagnosis: the Predict-HD study. J Neurol Neurosurg Psychiatry 2008;79(8):874-80. https://doi.org/10.1136/jnnp.2007.128728

3. Aylward EH, Sparks BF, Field KM, Yallapragada V, Shpritz BD, Rosenblatt A et al. Onset and rate of striatal atrophy in preclinical Huntington disease. Neurology 2004;63(1):66-72. https://doi.org/10.1212/01.WNL.0000132965.14653.D1

4. Ferrante RJ, Gutekunst CA, Persichetti F, McNeil SM, Kowall NW, Gusella JF et al. Heterogeneous topographic and cellular distribution of huntingtin expression in the normal human neostriatum. J Neurosci 1997;17(9):3052-63.

5. Ciarmiello A, Cannella M, Lastoria S, Simonelli M, Frati L, Rubinsztein DC et al. Brain white-matter volume loss and glucose hypometabolism precede the clinical symptoms of Huntington's disease. J Nucl Med 2006;47(2):215-22.

6. Rosas HD, Tuch DS, Hevelone ND, Zaleta AK, Vangel M, Hersch $\mathrm{SM}$ et al. Diffusion tensor imaging in presymptomatic and early Huntington's disease: selective white matter pathology and its relationship to clinical measures. Mov Disord. 2006; 21(9):1317-25. https://doi.org/10.1002/mds.20979

7. Basser PJ, Pierpaoli C. Microstructural and physiological features of tissues elucidated by quantitative-diffusion-tensor MRI.J Magn Reson. 1996;111(3):209-19. https://doi.org/10.1006/jmrb.1996.0086

8. Basser P, Pierpaoli C. Recollections about our 1996 JMR paper on diffusion anisotropy. J Magn Reson. 2011;213(2):571-2. https://doi.org/10.1016/j.jmr.2011.08.023

9. Klöppel S, Draganski B, Golding CV, Chu C, Nagy Z, Cook PA et al. White matter connections reflect changes in voluntary-guided saccades in pre-symptomatic Huntington's disease. Brain. 2008;131(1):196-204. https://doi.org/10.1093/brain/awm275

10. Paulsen JS, Nopoulos PC, Aylward E, Ross CA, Johnson H, Magnotta VA et al. Striatal and white matter predictors of estimated diagnosis for Huntington disease. Brain Res Bull. 2010;82(3-4):201-7. https://doi.org/10.1016/j.brainresbull.2010.04.003

11. Dumas EM, Bogaard SJ, Ruber ME, Reilman RR, Stout JC, Craufurd D et al. Early changes in white matter pathways of the sensorimotor cortex in premanifest Huntington's disease. Hum Brain Mapp. 2012;33(1):203-12. https://doi.org/10.1002/hbm.21205

12. Huntington Study Group. Unified Huntington's Disease Rating Scale: reliability and consistency. Mov Disord. 1996;11(2):136-42. https://doi.org/10.1002/mds.870110204 
13. Tumas V, Camargos ST, Jalali PS, Galesso AP, Marques Junior W. Internal consistency of a Brazilian version of the unified Huntington's disease rating scale. Arq Neuropsiquiatr. 2004;62(4):977-82. https://doi.org/10.1590/S0004-282X2004000600009

14. Brucki SM, Nitrini R, Caramelli P, Bertolucci PH, Okamoto IH. [Suggestions for utilization of the mini-mental state examination in Brazil]. Arq Neuropsiquiatr. 2003;61(3B):777-81. Portuguese. https://doi.org/10.1590/S0004-282X2003000500014

15. Duro D, Simões MR, Ponciano E, Santana I. Validation studies of the Portuguese experimental version of the Montreal Cognitive Assessment (MoCA): confirmatory factor analysis. J Neurol. 2010;257(5):728-34. https://doi.org/10.1007/s00415-009-5399-5

16. Gorenstein C, Andrade L, Vieira Filho AH, Tung TC, Artes R. Psychometric properties of the Portuguese version of the Beck Depression Inventory on Brazilian college students. J Clin Psychol. 1999;55(5):553-62. https://doi.org/10.1002/(SICI)10974679(199905)55:5<553::AID-JCLP3>3.0.CO;2-D

17. Tabrizi SJ, Langbehn DR, Leavitt BR, Roos RA, Durr A, Craufurd D et al. Biological and clinical manifestations of Huntington's disease in the longitudinal TRACK-HD study: cross-sectional analysis of baseline data. Lancet Neurol. 2009;899):791-801. https://doi.org/10.1016/S1474-4422(09)70170-X

18. Smith SM, Jenkinson M, Woolrich MW, Beckmann CF, Behrens TE, Johansen-Berg $\mathrm{H}$ et al. Advances in functional and structural MR image analysis and implementation as FSL. Neuroimage. 2004;23 Suppl 1:S208-19. https://doi.org/10.1016/j.neuroimage.2004.07.051

19. Rueckert D, Sonoda LI, Hayes C, Hill DL, Leach MO, Hawkes DJ. Nonrigid registration using free-form deformations: application to breast MR images. IEEE Trans Med Imaging. 1999;18(8):712-21. https://doi.org/10.1109/42.796284
20. Smith SM, Jenkinson M, Johansen-Berg H, Rueckert D, Nichols TE, Mackay CE et al. Tract-based spatial statistics: voxelwise analysis of multi-subject diffusion data. Neuroimage. 2006;31(4):1487-505. https://doi.org/10.1016/j.neuroimage.2006.02.024

21. Bohanna I, Georgiou-Karistianis N, Hannan AJ, Egan GF. Magnetic resonance imaging as an approach towards identifying neuropathological biomarkers for Huntington's disease. Brain Res Rev. 2008;58(1):209-25. https://doi.org/10.1016/j.brainresrev.2008.04.001

22. Mascalchi M, Lolli F, Della Nave R, Tessa C, Petralli R, Gavazzi C et al. Huntington disease: volumetric, diffusion-weighted, and magnetization transfer MR imaging of brain. Radiology. 2004;232(3):867-73. https://doi.org/10.1148/radiol.2322030820

23. Stoffers D, Sheldon S, Kuperman JM, Goldstein J, Corey-Bloom J, Aron AR. Contrasting gray and white matter changes in preclinical Huntington disease: an MRI study. Neurology. 2010;74(15):1208-16. https://doi.org/10.1212/WNL.0b013e3181d8c20a

24. Novak MJ, Seunarine KK, Gibbard CR, Hobbs NZ, Scahill RI, Clark CA et al. White matter integrity in premanifest and early Huntington's disease is related to caudate loss and disease progression. Cortex. 2014;52:98-112. https://doi.org/10.1016/j.cortex.2013.11.009

25. Rosas HD, Salat DH, Lee SY, Zaleta AK, Pappu V, Fischl B et al. Cerebral cortex and the clinical expression of Huntington's disease: complexity and heterogeneity. Brain. 2008;131(4):1057-68. https://doi.org/10.1093/brain/awn025

26. Weaver KE, Richards TL, Liang O, Laurino MY, Samii A, Aylward EH. Longitudinal diffusion tensor imaging in Huntington's disease. Exp Neurol. 2009;216(2):525-9. https://doi.org/10.1016/j.expneurol.2008.12.026

27. Poudel GR, Stout JC, Dominguez JF, Churchyard A, Chua P, Egan GF et al. Longitudinal change in white matter microstructure in Huntington's disease: the IMAGE-HD study. Neurobiol Dis. 2015;74:406-12. https://doi.org/10.1016/j.nbd.2014.12.009 